\title{
Transforming shrub waste into a high- efficiency adsorbent: Application of Physalis peruvian chalice treated with strong acid to remove the 2,4-dichlorophenoxyacetic acid herbicide
}

Jordana Georgin; Dison S. P. Franco; Matias Schadeck Netto; Daniel Allasia; Edson Luiz Foletto; Luis F. S. Oliveira; Guilherme Luiz Dotto

\begin{abstract}
In this study, the chalice generated from the production of the Physalis peruviana fruit was subjected to a treatment with sulfuric acid and applied in the adsorption of 2,4-Dichlorophenoxyacetic acid (2,4-D). The precursor, and the treated material before and after the adsorption, were analyzed by different techniques. After the acid treatment, it was found that the surface was changed from a smooth to an irregular surface with the presence of cavities with irregular size. The adsorption was favored at $\mathrm{pH}=2$ and with a dosage of $0.8 \mathrm{~g} \mathrm{~L}^{-1}$. The pseudo-second-order model was the best to represent kinetic data. The isothermal experiments were well represented by the Langmuir and Tóth models, reaching a high capacity of 244 and $320 \mathrm{mg} \mathrm{g}^{-1}$, respectively. The computed thermodynamic values show that the 2,4-D adsorption was spontaneous and exothermic. Overall, this study indicates that the Physalis peruviana chalice treated with strong acid presents great potential as an alternative material for the adsorption/removal of 2,4-D herbicide from liquid effluents.
\end{abstract}

\section{Keywords}

2,4-D; Herbicide; Physalis peruviana; Adsorption; Thermodynamic 